\title{
Strategizing sustainable development: the case of the Ural industrial regions
}

\author{
Irina Rakhmeeva $^{1 *}$, Ivan Antipin ${ }^{1}$ \\ ${ }^{1}$ Ural State University of Economics, 8 Marta str. 62/45, 620144 Yekaterinburg, Russian Federation
}

\begin{abstract}
The remit of the article is regional development strategizing. Regional development strategy as part of regional regulatory environment could ensure the task of sustainable development due to determining priorities for resource conservation, development of a "green" economy, and restoration of natural resources. This is especially important for the extractive economies of the Russian regions. On the contrary, the research revealed the preservation of extractive policies in most of the Ural regions. The manuscript contains the description of the ecological and economic position of the regions of the Ural macroregion, that have a high anthropogenic impact on the environment because of their nature of economy. We analysed the content of the development strategies of the regions of the Ural macroregion and the issues of sustainable development. The Chelyabinsk region and the Republic of Bashkortostan didn't include sustainable development in the top priorities. It leads them to stick their place in the tail of the National Environmental Rating of Russian Regions. Orenburg region's strategy conclude the most quality mechanisms for ensuring environmental safety in regional strategic documents. The author highlighted the comprehension of the deep interrelationships of ecological well-being with all spheres of human life in the development strategy of the Sverdlovsk region. The regional development strategy is an important mechanism for ensuring a balance between industrial growth and environmental conservation. Therefore, the authority of traditional industrial regions of the Urals should strengthen the component of sustainable development in their strategies.
\end{abstract}

\section{Introduction}

The set of characteristics of the modern Russian Federation determines the relevance of the research. First, the importance of the strategic approach in management is increasing.

Second, the objects of strategic planning are becoming more complex and the new objects (macroregion, parts of the subject of the Russian Federation, etc.) require specific approaches.

Third, there are no unified methodological approaches to strategizing the socioeconomic development of a territory in Russia.

Fourth, the authorities do not sufficiently involve various groups of stakeholders in the processes of strategizing the socio-economic development of a region.

${ }^{*}$ Corresponding author: smartreg66@gmail.com 
Economists, sociologists, regionalists, political scientists, and other researchers have developed many theories, models and approaches to analyse the process of strategizing the socio-economic development of a territory of various hierarchical levels, their individual territories, industries, etc.

The issues of studying the existing shortcomings of strategic planning for the Russian Federation are relevant despite the successes of recent decades in improving these processes $[1 ; 2$, p. 2].

Human economic activity related to extraction natural resources and transformation the biosphere since ancient times. The growth of human needs and productivity determined the increasing environmental load. A society and authority intervened purposeful in industrial activity when the biosphere's recover ability ceased to correspond to the damage caused by human. L.J. Ramirez Lopez and A.I. Grijalba Castro indicated the need for environmental planning in the space of the territory [3, p. 181].

The United Nations Conference on Environment and Development in 1992 triggered a boom of institutional adjustment process for shift to the new paradigm of sustainable development [4].

The impact of industry on the environment is local. This determines the relevance of local level measures and the focus of regionalists 'attention on this problem.

We emphasized significance of regulation in industrial regions with high ecological load [5], and in extractive economies regions with insufficient recovery measures [6, 7]. Therefore, the object of the research is the Ural macroregion. It is the main industrial centre of the country. 7 industrial regions are part of it.

The aim of the manuscript is to analyse the degree of inclusion of the sustainable development priority in the regional strategic goals in the Ural macroregion. We done 3 challenges. At first, to clarify the role of the regional development strategy in ensuring the sustainable development. Second task is to describe the ecological and economic state of the regions of the Ural macroregion. Third issue is to analyse the content of the development strategies of the regions of the Ural macroregion and to examine the degree of elaboration of the sustainable development priority in these documents.

\section{Materials and methods}

The methodology is based on regional and institutional economics.

The concept of high causality of the level and the sustainability of regional development by the quality of regional regulatory environment [8, p. 289] is the core of the research. The regional strategy is the heart of the regional regulatory environment. It forms the main development goals and determines the directions (tools) for achieving them, and coordinates development priorities [9, p. 1022]. "The stability of ecological and socio-economic environment depends on the level of economic activity measured by the capacity of territorial ecosystem" [10, p. 1029].

According to the normative framework approach, sustainable development is the provision of "a balanced solution to socio-economic problems and problems of preserving a favourable environment and natural resource potential in order to the needs of present and future generations" [Decree of the President of the Russian Federation No. 440 of 01.04.1996 "Concepts of the Transition of the Russian Federation to Sustainable Development"].

The regional development strategy is a key tool for the formation of a regional policy that can ensure the sustainable development of the territory. It should include a description of the current environmental situation and key problems, mechanisms for solving them, and indicators for the target state. Problems and contradictions in strategic planning did not arise spontaneously. There are no uniform rules for the formation (development and updating) of socio-economic development strategies, including uniform requirements for the composition 
of participants of the strategizing, in the Russian Federation and in the world community at present. This leads to a significant differentiation in the content and the quality of regional development strategies. The papers of Russian researchers [11-13] revealed methodological approaches and methods for the strategizing the socio-economic development of various territories (cities, regions, macroregions).

Regional authorities should involve all beneficiaries in the designing of strategies. The attraction of scientific and educational organizations will create a theoretical basis for the strategy [14, p. 102].

The key research method is the structural-logical monographic analysis of strategic documents. This method together with the regional analysis of the structure of economic and ecological conditions allows us to predict the prospects for the sustainable development of the territory.

The empirical basis of the study is the official regional development strategies.

The authors rely on the National Ecological Rating of Russian regions to comparing the ecological state of the regions of the Ural macroregion. The rating is based on the principles of sustainable development of the Declaration of The United Nations Conference on Environment and Development in 1992. The rating includes environmental protection, industrial-ecological and socio-ecological indexes.

The authors suggest characteristics of the ecological and economic system of the Ural macroregion.

The regions of the Ural macroregion are industrial. Manufacturing industries (metallurgy, metalworking, machine industry) are the key industries of the regions of the Ural macroregion. The gas and petrochemical industries are also developed in the Orenburg Region, Perm Krai, and the Republics of Bashkortostan and Udmurtia.

According to the study of the sustainability of the ecological and socio-economic environment of the Ural Federal District, "The Chelyabinsk region is the least stable, which is associated with both natural conditions and the specifics of the economic structure" [10, p. 1034].

The regions of the Ural macroregion have many mineral deposits. This determined the rapid growth of the mining industry and the extractive nature of the economy of these regions at the dawn of their formation in the historical context.

The industrial production were declining in the second decade of the XXI century in Russia as a whole and in the regions of the Ural macroregion [15, p. 29]. This leads to a decrease in the environmental load without targeted actions of local authorities.

The high level of industry requires large volumes of production and distribution of electricity, gas, and water. "Significant material flows in the electric power industry lead to a significant share of greenhouse gas emissions" in the Ural regions) [10, p. 1034].

Table 1. The position of the regions of the Ural macroregion in the National Environmental Rating.

\begin{tabular}{|c|c|c|}
\hline \multirow{2}{*}{ Region } & \multicolumn{2}{|c|}{$\begin{array}{c}\text { Place } \\
\text { Composite index: environmental protection, } \\
\text { industrial-ecological and socio-ecological indexes }\end{array}$} \\
\cline { 2 - 3 } & 2020 & 2015 \\
\hline Chelyabinsk region & 83 & 84 \\
& $46: 27,47,63$ & $36: 20,39,46$ \\
\hline Sverdlovsk region & 81 & 85 \\
& $47: 36,46,59$ & $36: 35,32,39$ \\
\hline Orenburg region & 72 & 75 \\
& $50: 31,41,70$ & $40: 27,29,62$ \\
\hline Kurgan region & 60 & 72 \\
& $55: 46,37,71$ & $41: 37,26,58$ \\
\hline
\end{tabular}




\begin{tabular}{|c|c|c|}
\hline $\begin{array}{c}\text { Republic of } \\
\text { Bashkortostan }\end{array}$ & 50 & 49 \\
& $58: 43,53,73$ & $44: 36,39,56$ \\
\hline Perm Krai & 25 & 28 \\
& $63: 50,60,73$ & $48: 43,47,53$ \\
\hline Republic of Udmurtia & 15 & 36 \\
& $65: 53,52,78$ & $46: 40,32,63$ \\
\hline
\end{tabular}

The analysis of the National Environmental Rating of Russian regions gives the following conclusions. The composite index and its components increased in all regions of the Ural macroregion over the past 5 years. The Republic of Udmurtia and the Kurgan Region were able to improve their positions on all directions in the rating significantly. Perm Krai, Sverdlovsk and Orenburg regions were able to rise to 3 places. The Perm Krai received the result due to successful work in all 3 areas of the rating. The Sverdlovsk and Orenburg regions increased the rating mainly due to the socio-ecological index, slightly due to the industrialecological index. The situation with nature protection has not changed in these two regions at the same time. The Chelyabinsk Region and the Republic of Bashkortostan remained roughly in the same positions.

\section{Results and discussions}

This section presented the results of analysis of the implementation of the priority of sustainable development in the strategies of the regions of the Ural macroregion.

The development strategy of the Chelyabinsk region until 2035 calls the unfavourable environmental situation in the region, the high environmental load from the organizations of ferrous and non-ferrous metallurgy, the high degree of accumulated damage to the environment as a weak side of the economy of the Chelyabinsk region. The key tools of the target scenario for the development of the Chelyabinsk region are the creation of favourable conditions for investment, the modernization of the economy, the formation of new high-tech industries and the growth of productivity. Creating a network of competitive economic centres (cities and urban agglomerations) for the economic and geological exploration of the territory of the Chelyabinsk region in the long term is a strategic priority. The development strategy of the Chelyabinsk region pays extraordinarily little attention to the task of ensuring environmental safety in comparison with other issues. A significant part of the ecological activities is focused on strengthening government control and monitoring.

The primary tasks of the Sverdlovsk region development are to improve the quality and standards of life of the population, to create favourable conditions for a long, safe, healthy, and prosperous life of citizens. The Government of the Sverdlovsk region considers the high level of environmental impact of technogenic factors as one of the most important problems. The balanced development is among the 3 development priorities. The direction of the development strategy of the Sverdlovsk region until 2030 "Balanced development" includes the purpose of sustainable environmental development of the territory. The "Clean Environment" project would solve this problem.

Improving the ecological situation is a strategic task of the priority of a comfortable living environment in the Orenburg region. A special chapter of the development strategy of the Orenburg region until 2030 covered environmental policy. It includes specific mechanisms and target indicators for improving the quality of the nature and living conditions of the population, reducing the ecological load on the natural complexes, and activating economic mechanisms for rational use of natural resources.

The development strategy of the Kurgan region until 2030 includes the priority of balanced spatial development. Ensuring environmental well-being is part of this priority. It includes the rational use and reproduction of mineral resources, the preservation of a 
favourable environment, water, forests, and biological diversity. The strategy describes the objectives and targets for each area. The authors consider the measures of the strengthen the requirements for the processing of extracted resources, and the involvement of waste in economic turnover in the strategy of the Kurgan region as essential.

The development strategy of the Republic of Bashkortostan until 2030 does not contain any identification of environmental problems in the region as significant for overcoming. The description of the regional ecological situation in the strategy highlights the more prosperous status of the Republic of Bashkortostan in comparison with other industrial leaders of the country. The development of a "green" economy, resource- and energy-saving technologies is a factor of the transition to a new model of economic growth in the strategy. The development strategy of the Republic of Bashkortostan focuses on measures to reduce the amount of greenhouse gases. It is also noted that the processing of secondary material resources is not developed in the republic and this issue needs to be worked out.

The environmental management section of the development strategy of Perm Krai until 2026 indicated the following problems: the increasing amount of household waste, the threat of environmental pollution and the low efficiency of the use of natural resources. Ensuring the safety of the ecological environment is one of the key tasks. However, the authors of the strategy didn't disclose the content of this task.

The basic and target development scenario of the Udmurt Republic until 2025 involves the active exploitation of available natural resources and does not contain a key priority of environmental safety. Ensuring the environmental sustainability of the territory and energy conservation are the sub-tasks of the direction "Reducing the infrastructure constraints of development".

We would like to say the following for discuss the problem.

The reflection of the priority of sustainability in the reginal development strategy determines the overall environmental policy of the regional authorities and the degree of further elaboration of this issue.

The regions of the Ural macroregion are highly industrial and have a significant anthropogenic impact on the environment. Therefore, the problem of environmental safety is presented in all regional development strategies. We noted the depth description of the relationship between environmental well-being and all spheres of human life in the development strategy of the Sverdlovsk region. The strategy of the Orenburg region includes the most quality mechanisms for implementing environmental policy.

The lack of environmental priority in the top strategic goals fixed the Chelyabinsk region in the tail of the National Environmental Rating and led to the loss of the one position by the Republic of Bashkortostan.

Regions with extractive economies (developed oil and gas production complex) continue to focus on the extensive exploitation of minerals in their strategies. This is contrary to the conditions of sustainable development.

\section{Conclusions}

The region's development strategy is an important mechanism for ensuring sustainable development and a balance between industrial growth and environmental safety. Traditionally, the industrial regions of the Urals should strengthen the sustainable development component in their strategies.

L.A. Sverdrup showed on the example of Norway that eenvironmental considerations must be institutionalised into the existing political system [16].

The declaration of specific sustainable development goals in the regional development strategy contributes to their further inclusion in the program documents and allocation of budget funding. The development strategy of the region as the central link of the regional 
regulatory environment determines the contours of innovative and technological development and the formation of a "green" economy, lean manufacturing [17], impact on corporate strategy [18].

Digital tools can improve the efficiency of the resources exploitation [19], the organization of monitoring and control [20].

The authors formulated several recommendations aimed at improving the quality and viability of socio-economic development strategies, and increasing the sustainability of territorial development based on the results of the research of the processes of strategic planning and strategic management in the Russian Federation [21], and the development strategies of the regions of the Ural macroregion.

First, regional authorities should pay serious attention to the analysis of the environment of the object of strategic planning. The quality and depth of trend analysis are the most important conditions for the optimal determination of the directions of strategizing and the viability the regional socio-economic development strategies.

Also, the stage of environmental analysis requires a clear choice and application of strategic analysis methods. A large portion of the socio-economic development strategies of municipalities and regions of the Russian Federation contain SWOT-analysis, but it is performed correctly rarely. The postulates of the "classical" SWOT-analysis of the Harvard School of strategic Planning are fundamental. It is also possible to use significance coefficients for each of the SWOT-analysis factors. We recommend to apply other methods (PEST-analysis, strategic synthesis, etc.) in addition to SWOT-analysis.

Second, the goal-setting stage should include formulation a mission and decomposition of goals clearly. The general (key, top, major) strategic goal is decomposed into lower-level goals. As a rule, the goals of the first level are the goals of strategic directions, the goals of the second level are the goals of strategic programs, the goals of the third level are the goals of strategic projects. Compliance with such a hierarchical structure of goals ensures the relationship between strategic and operational (tactical) tasks and activities.

Third, regional authorities should elaborate the list of strategic directions of the socioeconomic development in details, including a system of performance indicators. The achievement of indicators characterizes the degree of implementation of the strategy, the results of achieving of strategic goals and completing strategic tasks annually. We recommend to include performance indicators for each strategic direction. The principles of sustainable development dictate the need to include economic, social, and environmental development among the strategic directions. Regional authorities should actively engage in the development of environmental education of the population and the ecological culture of entrepreneurs. These tasks can be implemented within the framework of the state information policy [22].

Fourth, the regional socio-economic development strategy should provide all the processes in areas of strategic planning object (municipality, region of the Russian Federation, the country as a whole, etc.). The Russian local authorities consider only legally defined powers and competencies often.

Fifth, we recommend specifying the subjects, mechanisms, principles, and stages of monitoring and controlling the implementation of the socio-economic development strategy. A scheme for the organization of the strategic management corresponds to the strategic directions, priorities of strategic development and the actual structure of the authorities. Responsible executors and co-executors of the strategy are not only the local authorities but also absolutely all stakeholders.

The study of spatial development of the entire country and its territories has been popular in recent years in the Russian Federation. Accordingly, the sixth recommendation is coordination of socio-economic and territorial development in the socio-economic 
development strategies. It means that each strategic direction should contain guidelines for spatial development.

The authors concluded that the processes of strategic planning and strategic management play a crucial role in the system of long-term planning. The strategizing could generate positive impulses in the socio-economic development of the Russian Federation and its regions and require further improvement. The success of the socio-economic development of the Russian regions and country depends on the optimality (efficiency) of the strategic planning and strategic management among other things.

\section{Acknowledgements}

The reported study was funded by RFBR, project number 20-010-00824 "Incremental approach to the formation and implementation of strategies for the socio-economic development of regions of different hierarchical levels of the Russian Federation: Uniform rules for strategizing”.

\section{References}

1. E.B. Lenchuk, Innovations, 2 (256), 24 (2020)

2. Ya.P. Silin, Ye.B. Dvoryadkina, I.A. Antipin, Upravlenets - The Manager, 9(6), 2 (2018)

3. L.J. Ramirez Lopez, A.I. Grijalba Castro, Sustainability, 13(1), 181 (2021)

4. T.G. Ribeiro, V.J. Rodrigues, Environmental Politics, 6(1), (1997)

5. A.S. Nikitina, A.V. Ruchkin, N.N. Startseva, O.M. Trofimova, N.K. Shemetova, N.A. Yurchenko, International Transaction Journal of Engineering, Management and Applied Sciences and Technologies, 10(14), 10A14O (2019)

6. F. Ekardt, J. Stubenrauch, B. Garske, B. Jacobs, Land, 9(3), 83 (2020)

7. P.A. Gurianov, Journal of Mining Institute, 208, 18 (2014)

8. I.I. Rakhmeeva, R-economy, 6(4), 280 (2020)

9. Yu. G. Lavrikova, V.V. Akberdina, A.V. Suvorova, Economy of Region, 15(4), 1022 (2019)

10. A.Y. Davankov, D.Y. Dvinin, Y.A. Postnikov, Economy of Region, 12(4), 1029 (2016)

11. N.Yu. Vlasova, Administrative Consulting, 3 (15), 18 (1999)

12. A.L. Gaponenko, Spatial Economics, 4, 40 (2005)

13. V.V. Kafidov. Moscow: Delo ANE (2015)

14. D. Gallardo-Vázquez, J.A. Folgado-Fernández, Land, 9(4), 102 (2020)

15. I.A. Antipin, N.Yu. Vlasova, O.Yu. Ivanova, Upravlenets - The Manager, 11(6), 28 (2020)

16. L.A. Sverdrup, Environmental Politics, 6(1), 54 (1997)

17. N.N. Trofimova, European Proceedings of Social and Behavioural Sciences EpSBS, $1316(2020)$

18. Zaytsev, D. Rodionov, N. Dmitriev, R. Faisullin, Academy of Strategic Management Journal, 19(4), 12 (2020)

19. I.A. Magomedov, A.M. Bagov, A.L. Zolkin, European Proceedings of Social and Behavioural Sciences EpSBS, 553 (2020)

20. Agumbayeva, E. Chmyshenko, N. Pulyaev, D. Bunkovsky, K. Kolesov, E. Amirova, Journal of Advanced Research in Law and Economics, 10-6(44), 1861 (2019)

21. I. Antipin, N. Vlasova, Journal of New Economy, 21(3), 73 (2020)

22. E. Ustinovich, Comparative Politics Russia, 4(2), 4 (2013) 